\title{
ESTRATÉGIAS DE RESOLUÇÃO DE CONFLITOS ADOTADAS PELOS ENFERMEIROS: ESTUDO DE ALGUNS FATORES DETERMINANTES
}

\author{
Paula Pinho $^{1}$ \\ Carlos Albuquerque ${ }^{2}$
}

\begin{abstract}
Resumo
Enquadramento: As mudanças de políticas na saúde $e$ as alterações na profissão e carreira de enfermagem interferem na dinâmica e estabilidade futura dos enfermeiros. O presente estudo teve como objetivo conhecer alguns fatores determinantes das estratégias de resolução de conflitos adotadas pelos enfermeiros.

Material e Método: Realizou-se um estudo de natureza quantitativa, descritivo-correlacional e transversal, com recurso a uma amostra não probabilística e por conveniência, composta por com 102 enfermeiros a exercer funções em Unidades de Saúde, maioria do sexo feminino (82,4\%) e com idade média de 39,33 anos e desvio padrão 9,226. O instrumento de colheita de dados incorporou três escalas aferidas e validadas para a população portuguesa: Questionário Empenhamento Organizacional, Escala Empenhamento Profissional e Inventário Estratégias de Resolução de Conflitos que avalia como os indivíduos lidam com as situações conflituais perante superiores (Forma A), subordinados (Forma B) e colegas (Forma C).

Resultados: A maioria dos enfermeiros apresenta scores moderados a elevados de empenhamento organizacional $e$ profissional. Confirmam-se as hipóteses de que algumas variáveis sociodemográficas e profissionais predizem as estratégias de resolução de conflitos adotadas pelos enfermeiros. Há uma correlação positiva entre idade e estratégia evitação face ao chefe; género e estratégia dominação face aos subordinados; formação em

\footnotetext{
${ }^{1}$ Unidade de Saúde Familiar Lusitana.

${ }^{2}$ Escola Superior de Saúde de Viseu. Email: cmalbuquerque@gmail.com
} 
gestão e estratégia dominação face ao chefe e subordinados; categoria profissional de enfermeiro e enfermeiro graduado $e$ estratégia evitação face ao chefe e aos colegas; local de trabalho e estratégia dominação face ao chefe, subordinados e colegas; tempo de serviço e estratégia evitação face ao chefe e aos colegas. $O$ empenhamento organizacional e o empenhamento profissional estão positivamente correlacionados entre si e determinam as estratégias de resolução de conflitos adotadas pelos enfermeiros.

Conclusão: Os resultados asseguram a necessidade favorecer $e$ estimular o empenhamento afetivo pelas consequências positivas que ele acarreta na organização e na profissão. O desempenho organizacional beneficia com a estimulação do conflito sob determinadas condições e que a gestão construtiva dos conflitos é um elemento essencial para a eficácia organizacional.

Palavras-chave: conflitos, enfermeiros, empenhamento.

\section{Abstract}

Framework: Changes in health policies and changes in nursing profession and career interfere in the dynamics and future stability of nurses. The present study aimed to some determinant factors of the conflict resolution strategies adopted by nurses.

Material and Method: A quantitative, descriptive-correlational and cross-sectional study was performed using a non-probabilistic and convenience sample, composed of 102 nurses to perform functions in Health Units, most of them female (82.4\%) and with average age of 39.33 years and standard deviation 9,226. The data collection instrument incorporated three scales validated for the Portuguese population: Organizational Commitment Questionnaire, Professional Engagement Scale, and Inventory Conflict Resolution Strategies that assess how individuals deal with conflicting situations with superiors (Form A), subordinates (Form B) And colleagues (Form C).

Results: Most nurses have moderate to high levels of organizational and professional commitment. The hypothesis is confirmed that some sociodemographic and professional variables predict the conflict resolution strategies adopted by nurses. There is a positive correlation between age and strategy avoidance versus the boss; Gender and domination strategy vis-à-vis subordinates; 
Training in management and strategy domination vis-à-vis the boss and subordinates; Professional category of nurse and graduate nurse and avoidance strategy towards boss and colleagues; Workplace and domination strategy vis-à-vis the boss, subordinates and colleagues; Time of service and avoidance strategy vis-à-vis boss and colleagues. The organizational and professional commitment are positively correlated with each other and determine the conflict resolution strategies adopted by nurses.

Conclusion: The results ensure the need to favor and stimulate the affective commitment for the positive consequences that it entails in the organization and in the profession. Organizational performance benefits from the stimulation of conflict under certain conditions and that constructive conflict management is an essential element for organizational effectiveness.

Keywords: Conflicts, nurses, commitment.

\section{INTRODUÇÃO}

O conflito é entendido como um fenómeno inevitável na vida organizacional, emergindo, desta forma, nas relações entre indivíduos de um mesmo grupo, entre grupos, entre os diferentes níveis organizacionais e mesmo entre organizações. A interação e a interdependência entre os diferentes grupos profissionais, indivíduos oriundos de diversos extratos sociais, o caráter específico dos serviços prestados, as relações de poder existentes e a existência de diferentes ideias e valores dos vários profissionais que constituem uma organização de saúde, geram tendências para a ação, constituindo-se como uma fonte potencial de conflito (Deutsch, 2003). Por outro lado, a complexidade de uma organização de saúde onde se interligam diferentes competências, conhecimentos, capacidades e atividades, de cuja adequada coordenação depende o alcance dos objetivos estabelecidos, fomenta muitas vezes o conflito organizacional.

Nesta premissa e considerando a visão clássica do conflito, é interiorizado como um importante desiderato de qualquer organização, procurar evitar, com veemência, esse conflito em virtude do mesmo apresentar consequências nefastas à dinâmica organizativa, sendo visto 
como um entrave ao bom desenvolvimento organizacional. Já uma visão mais recente encara o conflito organizacional, não só como um dado factual mas também como uma dimensão que é necessário encorajar em termos de surgimento, pois sabe-se que a sua existência poderá ser saudável, desde que este se mantenha dentro de determinados "limites”, no pressuposto de que o conflito é algo de benéfico para estimular a inovação e criatividade dos comportamentos, das atitudes e das cognições. Assim, se as organizações o conseguirem, então estarão a contribuir para o seu desenvolvimento e para o crescimento dos profissionais que as integram e, ao mesmo tempo, a conduzirem o seu desempenho em direção aos objetivos traçados quer por si quer pelos vários grupos que constituem a organização.

Esta última argumentação é atualmente assumida por diversos autores, ao considerarem que ter níveis dirigíveis de conflito é algo positivo, podendo ser encarado como um indicador de gestão efetiva e eficaz de uma organização (Cunha et al., 2003a; McIntyre, 1991; Pruitt, 1971; Rahim \& Bonoma, 1979; Rahim \& Serrano, 1996). Neste pressuposto, Rahim (2002) refere que o que é preciso para as organizações contemporâneas é a gestão de conflitos e não a resolução de conflitos. A gestão de conflitos não implica necessariamente a evasão, redução ou cessação dos conflitos. Trata-se de conceber estratégias eficazes a nível macro, para minimizar as disfunções de conflito e de reforçar as funções construtivas do conflito, a fim de melhorar a aprendizagem e eficácia numa organização.

Adequadamente geridos, os conflitos, podem ser uma força criativa para o indivíduo e para a organização, pois as diferenças de opinião são valiosas fontes de fertilização cruzada (Penley \& Gould, 1988). Por outras palavras, o conflito apresenta possibilidades interessantes sobre o futuro, se for gerido de forma positiva, construtiva, porque as situações difíceis e os relacionamentos são considerados com o que faz, verdadeiramente, as pessoas crescer e reforçar as suas relações, mais do que aumentar os custos das organizações (Chen \& Tjosvold, 2002). Assim, estas têm cada vez mais, movido esforços, não para eliminar o conflito, mas para aumentar a gestão eficaz de conflitos, reconhecendo que o conflito é apenas um subproduto esperado (e às vezes até desejável) dos processos organizacionais (Higinite et al., 2002).

As estratégias de gestão de conflitos podem ser definidas como o conjunto de respostas dado pelos envolvidos perante a emergência de 
ideias, opiniões e/ou objetivos divergentes (DeChurch \& Marks, 2001; Pruitt \& Rubin, 1986).

Vários modelos, com diferentes estilos de lidar com o conflito organizacional, foram propostos ao longo dos anos por teóricos organizacionais. O modelo de cinco estilos de gestão de conflitos foi primeiramente concebido por Blake e Mouton em 1964, Thomas, 1992; Blake e Mouton, 1997 (citador por Rahim, 2001), e foi baseado em duas dimensões: preocupação com a produção e preocupação com as pessoas. As dimensões propostas por Rahim (2001) são “interesses próprios” e “interesses dos outros”. A combinação destas dimensões produz cinco estilos de administração de conflitos.

\section{Figura I}

Modelo Bidimensional de Estilos de Gestão de Conflitos

(Adaptado de Brahnam et al., 2005)

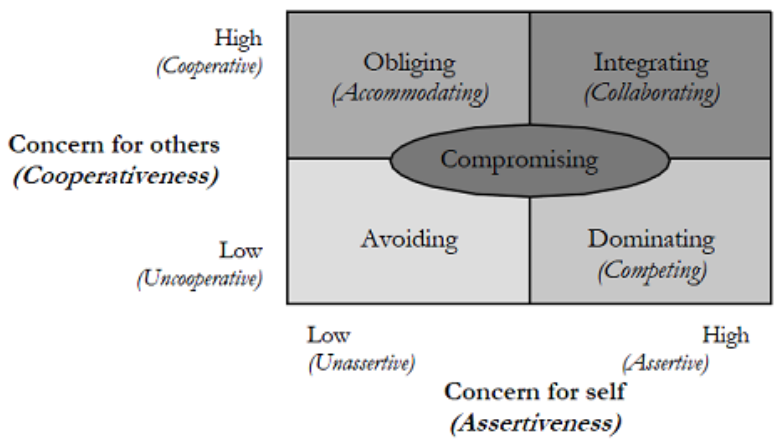

Por se tratar de um fenómeno complexo e dotado de um dinamismo muito próprio, há que ter em linha de conta todo um conjunto de fatores que surgem quando nos propomos estudá-lo, tais como a sua formação e causas, a comunicação, poder e liderança, assim como os indivíduos envolvidos vivenciam e sentem o fenómeno em causa. De acordo com Rahim (2001) as características dos cinco estilos de gestão de conflitos podem ser resumidas da seguinte forma:

O estilo dominação - corresponde a uma grande preocupação com interesses próprios e baixa preocupação com interesses dos outros, onde uma das partes procura satisfazer seus interesses à custa da outra parte. Trata-se de uma personalidade assertiva e não cooperativa porque uma das partes em conflito é agressiva e tenta satisfazer os seus interesses, 
independentemente do impacto sobre a outra parte envolvida no conflito. Uma pessoa dominadora ou competitiva vai ao limite a fim de alcançar seus objetivos e, como resultado, ignora as expectativas ou necessidades das outras partes envolvidas.

O estilo integração - predominante quando ambas as partes em conflito desejam satisfazer totalmente os interesses de todas as partes. Este estilo corresponde a uma grande preocupação com interesses próprios e dos outros. Trata-se de uma personalidade assertiva e cooperativa resultando em "ganha-ganha", em que cada parte envolvida no conflito deseja satisfazer plenamente as necessidades de todas as partes envolvidas, trabalhando em conjunto, trocando informações para encontrar soluções aceitáveis para ambas as partes.

O estilo compromisso - marcado por ações de "dar e receber", onde ambas as partes abrem mão de algo com o intuito de encontrar um resultado aceitável para ambos. Este estilo corresponde a uma moderada preocupação com interesses próprios e dos outros. Trata-se de uma personalidade assertiva e cooperativa média, em que se busca uma solução de meio-termo e onde ambas as partes têm "algo para dar" e "algo para receber”, procurando-se soluções mutuamente aceitáveis.

O estilo evitação - associado com a retirada, ignorância ou desatenção face à situação conflituante. Uma pessoa que evita o conflito falha em satisfazer seus próprios pontos de vista, bem como os da outra parte envolvida. Trata-se de uma personalidade não assertiva e não cooperativa, em que o desfecho da situação conflitual é normalmente "perde-perde", porque ambas as partes se abstêm de comunicar as suas necessidades e consequentemente não são atendidas.

O estilo acomodação - associado a minimizar as diferenças, ao mesmo tempo que se maximizam os fatores comuns, para que parte oposta seja satisfeita. A pessoa acomodada negligencia o seu próprio ponto de vista em favor da outra parte. Trata-se de uma personalidade assertiva e não cooperativa, em que a solução do conflito resulta em "perde-ganha", traduzindo-se por autossacrifício dos próprios interesses para satisfazer os interesses do outro, desenvolvendo atitudes de aceitação da vontade do adversário. Os indivíduos procuram o consentimento e aprovação do outro, manifestando ansiedade para ser útil e conseguir a aprovação e apoio dos outros. Estes indivíduos obedecem às ordens de outras pessoas mesmo quando preferiam não o fazer.

Entre os cinco estilos de resolução de conflitos descritos, a literatura parece favorecer o uso de estilo colaborativo/integrativo e recorda que as 
estratégias de gestão colaborativa/integrativas geram maior qualidade decisões do que as estratégias de distribuição (Bettenhausen, 1991; Brahnam et al., 2005; Filley, 1978; Jones \& White, 1985; Lovelace et al., 2001; Thomas, 1977).

Em suma, a estratégia de gestão de conflitos adotada deve ter como objetivo manter níveis razoáveis de conflito, de forma a estimular processos organizacionais como a criatividade e aprendizagem organizacional (Robbins, 2002). No entanto, não existe um estilo definido pelos investigadores que seja amplamente eficaz, pois numa situação conflitual concreta uma estratégia que se pode mostrar eficaz, noutra situação pode tornar-se altamente ineficaz. Rahim (2003), defende que a um determinado nível ótimo de conflito, corresponde uma elevada performance de trabalho, alertando no entanto para a necessidade de se desenvolverem estratégias de gestão de conflitos que se traduzam num aumento da efetividade organizacional. Menciona também que a gestão adequada dos conflitos, além de se relacionar com a capacidade de contribuir para o desempenho dos grupos e organização, satisfaz concomitantemente as necessidades sociais, morais e éticas dos elementos do grupo ou da organização, tendo como ponto de partida o empenhamento organizacional.

Vários estudos de diferentes autores reforçam o empenhamento organizacional como a condição em que o individuo aceita e interioriza os objetivos e valores de uma organização e como vê a função organizacional em termos da sua contribuição para esses objetivos e valores, para além de quaisquer instrumentalismos pessoais que possam reforçar o seu contributo (DeCottis \& Summers, 2007).

A importância de compreender o conceito de empenhamento organizacional deve-se à evidência de que ele é responsável pelas atitudes e comportamentos, como a assiduidade, a pontualidade, a intenção de abandonar a organização, as atitudes face à mudança, o desempenho do colaborador, os comportamentos de cidadania organizacional, os comportamentos de negligência e de abandono e o desempenho da organização (Allen \& Meyer, 1996; Allen e Meyer, 2000; Meyer, 1997; Meyer \& Herscovitch, 2001; Rego \& Souto, 2002). Rego (2003) afirma que a lógica que lhe está subjacente segue uma matriz simplista: inseridas em ambientes turbulentos e competitivos, as organizações de colaboradores que adotem comportamentos espontâneos de respostas a problemas, inovadores e criativos, que se identifiquem com a organização 
e que atuem como bons cidadãos organizacionais, tornam-se mais competitivas.

Allen e Meyer (1991) revelam a ideia de que o empenhamento organizacional é um estado psicológico que caracteriza o relacionamento do colaborador com a organização e tem implicações na decisão de continuar membro da organização. Os fundamentos consensuais entre os investigadores, para a definição de empenhamento organizacional, são: o desejo de permanecer membro da organização; o orgulho por pertencer à organização; a identificação com os objetivos, metas e valores da organização; o envolvimento, o esforço e o empenho exercido a favor da organização.

A partir da década de noventa tornou-se um consenso geral o facto de que o empenhamento organizacional é um constructo multidimensional. A partir da análise das diversas definições sobre o tema, Meyer e Allen (1991) notaram que estas refletiam três grandes áreas: Empenhamento afetivo - referindo-se a um envolvimento emocional do empregado em que ocorre uma identificação com a organização: empregados com um forte comprometimento afetivo permanecem na organização porque assim o querem; Empenhamento instrumental - referindo-se a um comprometimento percebido como custos associados por deixar a organização: empregados cujo vínculo principal com a organização é baseado no empenhamento instrumental, permanecem na organização porque precisam; Empenhamento normativo - refletindo um sentimento de obrigação de permanecer na organização: empregados com um alto nível de comprometimento normativo sentem que devem permanecer na organização.

Numa outra perspectiva é relevante, de igual modo, contextualizar a importância do empenhamento profissional, apesar da falta de consenso quanto á sua delimitação conceptual. A falta de consenso na definição e medição do empenhamento na profissão é bem percetível na análise da literatura sobre este tema e decorre do facto de cada autor avançar com uma concetualização própria, sem a preocupação de integrar conceitos já existentes. A falta de clarificação deste conceito tem levado a que vários termos sejam usados com o mesmo objetivo de identificar a importância da ocupação na vida do indivíduo, nomeadamente o empenhamento na ocupação, o empenhamento na carreira e o empenhamento na profissão. Porém, e apesar da discussão teórica, há um ponto consensual entre as diferentes abordagens: o empenhamento profissional ou o empenhamento na carreira, reflete a ligação psicológica do indivíduo em relação à 
profissão e/ou carreira. Aranya e Ferris (1983) e Morrow e Wirth (1989) defendem o empenhamento profissional como a intensidade relativa da identificação e envolvimento numa profissão. Para estes autores o empenhamento profissional pressupõe: a crença e aceitação dos objetivos e valores de uma profissão; a prontidão em exercer um esforço em prol dela e o desejo de permanecer na profissão. Já Blau et al. (1993), referem que o empenhamento profissional envolve a atitude, incluindo afeto, crença e intenção comportamental, em relação à profissão. Já Blau et al. (1993) encaram o empenhamento como um construto unidimensional, como uma ligação afetiva em relação à profissão. Estes autores consideram ainda o empenhamento profissional constituído por três dimensões: a dimensão afetiva, a dimensão instrumental e a dimensão normativa. O empenhamento profissional afetivo refere-se à identificação e envolvimento nos objetivos da profissão, assim como ao afeto em relação à profissão. O empenhamento profissional instrumental diz respeito aos investimentos feitos na profissão e que seriam perdidos caso a abandonássemos bem como à perceção de ausência de alternativas em termos de profissão. O empenhamento profissional normativo centra-se, então, no dever e responsabilidade sentidos e que levam o indivíduo a permanecer na profissão escolhida. O conceito adotado neste estudo segue a matriz defendida por Langford (1979), ao considerar o empenhamento profissional como um constructo que agrega os seguintes três componentes: "Interesse", que traduz a importância e prazer da profissão de enfermagem para o enfermeiro; "Relevância da Enfermagem como profissão”, que significa a apreciação e pertinência da enfermagem, numa perspetiva pessoal e social; e "Desafio", que pretende traduzir o quanto a enfermagem é aliciante e estimulante para o enfermeiro.

Tendo por base o enquadramento teórico anteriormente descrito, salientamos que o principal objetivo deste estudo foi avaliar o impacto de algumas variáveis de contexto demográfico e de empenhamento organizacional e profissional na implementação de estratégias de resolução de conflitos adotadas pelos enfermeiros, em contexto organizacional.

\section{MATERIAL E MÉTODOS}

Em qualquer investigação é essencial proceder ao enquadramento da metodologia, que pressupõe um processo racional e um conjunto de técnicas ou de meios que permitem realizar a investigação. Neste 
pressuposto, e partindo do princípio de que a seleção do instrumento metodológico se deve adequar ao problema a ser estudado, à natureza dos fenómenos, ao objeto da pesquisa, à operacionalização dos objetivos delineados e, ainda, à equipa humana e outros elementos que possam surgir no campo da investigação (Pestana \& Gageiro, 2008), a investigação levada a efeito insere-se num tipo de estudo não experimental, de natureza quantitativa, transversal, seguindo uma via descritivo-correlacional. Recorreu-se a uma amostra não probabilística e por conveniência, constituída por 102 enfermeiros, com exercício de funções desenvolvidas em instituições de saúde inseridas na Região NUT II - Centro e NUT III Dão-Lafões.

Como variável dependente foram consideradas as estratégias de resolução de conflitos e como variáveis independentes o empenhamento organizacional, o empenhamento profissional e ainda variáveis de contexto sociodemográfico e profissional. O instrumento de colheita de dados, com incorporação de medidas de avaliação aferidas e validadas para a população portuguesa, era constituído por: uma ficha de caracterização sociodemográfica; uma ficha de caracterização profissional; Escala de avaliação do empenhamento organizacional - "Organizational Commitment Questionnaire” (OCQ), de Meyer et al. (1993); Escala de avaliação do empenhamento profissional "Attitudinal Commitment Scale" (ACS), desenvolvida por Langford (1995, citado por Jones, 2000) e Escala de avaliação dos estilos de gestão de conflitos "Rahim Organizational Conflict Inventory - II" (ROCI-II), através da qual se pretende medir de que modo os sujeitos lidam com situações conflituais perante superiores (forma A), subordinados (forma B) e colegas (forma C).

Previamente à colheita de dados foi solicitado o parecer de uma comissão de ética, bem como expresso formalmente o consentimento informados dos enfermeiros participantes no estudo. $\mathrm{O}$ tratamento estatístico dos dados referentes foi efetuado informaticamente utilizando o programa Statistical Package for the Social Sciences (SPSS), versão 21.0 para Windows.

\section{APRESENTAÇÃO DOS RESULTADOS}

\subsection{Análise descritiva}

Os resultados do estudo revelaram uma amostra constituída por 102 enfermeiros, na sua maioria do género feminino (82,4\%), casados $(70.5 \%)$ e com uma média de idades de 39,33 anos ( $\mathrm{DP}=9.226$ ). $74.5 \%$ dos enfermeiros têm filhos e destes 63,5\% têm dois ou mais filhos. Quanto ao 
grau académico e formação profissional: 79,4\% são licenciados, 10,8\% são mestres em Gestão e Administração de Unidades de Saúde, 18,2\% em Família e Sistemas Sociais, 9,1\% em Enfermagem Transcultural, 9,1\% em Educação para a Saúde 9,1\% em Sociopsicologia da Saúde e 9,1\% em Saúde Ocupacional, $7,8 \%$ têm uma pós graduação para além da licenciatura, 62,5\% pós-graduação em Urgência e Emergência, 12,5\% pósgraduação em Família e Sistemas Sociais, 12,5\% em Nutrição Clinica e $12,5 \%$ em Cuidados Continuados e apenas $2 \%$ possuem grau de bacharel.

Do total da amostra, 24,48\% dos enfermeiros têm Curso de Especialização em Enfermagem e destes 37,5\% em Saúde Comunitária, 29,2\% em Saúde Infantil e Pediátrica, 16,7\% em Saúde Materna e Obstétrica, 12,5\% em Reabilitação e 4,2\% em Saúde Mental e Psiquiátrica. $81,4 \%$ dos enfermeiros não tem formação específica em gestão e apenas 18,5\% o têm. Quanto à caracterização profissional concluímos que: $50 \%$ dos enfermeiros são graduados, $28,4 \%$ são enfermeiros, $14,7 \%$ são enfermeiros especialistas e 6,9\% são enfermeiros chefes/coordenadores.

No que se refere ao tipo de unidade onde exercem funções: $49 \%$ dos enfermeiros exercem funções numa UCSP, 20,6\% numa USF Modelo B, 18,6\% numa USF Modelo A, 6,9\% numa SUB, 2,0\% numa USP, 2,0\% no Conselho Clínico do ACES e apenas 1,0\% numa UCC. Em relação ao vínculo laboral: 72,5\% possui contrato de trabalho de funções públicas e $27,5 \%$ possui contrato de trabalho a termo certo. Relativamente à existência de duplo emprego: 82,4\% não trabalha noutro local para além da unidade de saúde, enquanto 17,6\% tem um segundo emprego.

Relativamente à área de desempenho de funções, constatamos que: $74,6 \%$ exerce funções em cuidados de enfermagem gerais, $7,8 \%$ em cuidados de enfermagem especializados, 7,8\% dos enfermeiros acumulam funções relativas aos cuidados de enfermagem gerais, cuidados de enfermagem especializados e funções de gestão nas respetivas unidades onde trabalham e 5,9\% exercem exclusivamente funções de gestão.

O tempo de exercício profissional oscila entre um mínimo de 3 anos e um máximo de 36 anos de serviço, sendo que o tempo médio de exercício profissional é de 16,55 anos ( $\mathrm{DP}=9.394)$.

O rendimento mensal médio líquido varia entre um mínimo de 800 euros e um máximo de 2600 euros mensais e em média é de 1228,45 euros $(\mathrm{DP}=346.588)$, verificando-se que os enfermeiros têm um rendimento mensal médio superior ao das enfermeiras. 
A caracterização inerente ao empenhamento organizacional evidencia que $65,6 \%$ dos inquiridos apresentam níveis moderados de empenhamento, 30,5\% apresentam níveis elevados e 3,9\% apresentam níveis baixos. Quanto ao empenhamento profissional podemos concluir que: 60,8\% dos inquiridos apresentam níveis moderados e 39,2\% apresentam níveis elevados, não expressando níveis baixos nenhum dos enfermeiros inquiridos.

Relativamente às estratégias de resolução de conflitos podemos verificar que as médias nas estratégias dominação (13.77) e acomodação (19.78) são mais elevadas na forma $A$, o que revela que os enfermeiros adotam mais as estratégias de resolução de conflito dominação e acomodação face ao chefe. A média nas estratégias integração (24.47) e compromisso (13.83) são mais baixas na forma A, ou seja, os enfermeiros usam menos as estratégias integrativas e de compromisso quando em situação conflitual com o chefe. A média na estratégia evitação (27.70) é mais elevada na forma $\mathrm{B}$, pelo que podemos afirmar que os enfermeiros adotam mais as estratégias de evitação no confronto com os subordinados. A média nas estratégias integração (28.44) e compromisso (14.22) são mais elevadas na forma $C$, ou seja os enfermeiros adotam mais as estratégias integrativas e de compromisso quando a situação conflitual surge com os colegas. A média na estratégia dominação (12.97) é mais é baixa na forma $\mathrm{C}$, ou seja os enfermeiros adotam menos a estratégia dominação quando a situação conflitual surge com os colegas.

\subsection{Análise inferencial}

O estudo de associação entre as variáveis permite-nos concluir que existem efeitos significativos das variáveis sociodemográficas (género, grupo etário, formação académica e formação em gestão) na adoção de algumas estratégias de resolução de conflitos adotadas pelos enfermeiros. Em concreto, os resultados permitiram inferir que:

- Género - os enfermeiros usam mais a estratégia dominação - face aos subordinados comparativamente às enfermeiras $(t=2,136, p=, 035)$;

- Grupo etário - os enfermeiros mais jovens adotam mais a estratégia - evitação face ao chefe comparativamente aos enfermeiros com idades mais avançadas ( $\mathrm{F}=3,501 ; \mathrm{p}=, 034)$;

- Formação académica - os enfermeiros com grau académico de bacharel adotam mais frequentemente a estratégia - dominação face ao chefe, quando comparados com os enfermeiros com grau académico de mestre ( $F=2,519 ; \mathrm{p}=, 049)$; 
- Formação em gestão - os enfermeiros com formação em gestão adotam de forma mais continuada a estratégia - dominação face ao chefe $(\mathrm{t}=2,424, \mathrm{p}=, 020)$ e subordinados $(\mathrm{t}=2,166, \mathrm{p}=, 033)$.

Em relação às variáveis profissionais (categoria profissional, local de trabalho, tempo de exercício profissional e área de desempenho de funções), verificamos que existe um efeito significativo destas variáveis sobre as estratégias de resolução de conflitos adotadas pelos enfermeiros. Em suma, as estratégias de resolução de conflitos adotadas são influenciadas, de forma estatisticamente significativa, pelas variáveis profissionais, revelando os resultados que:

- os enfermeiros com a categoria de enfermeiro e enfermeiro graduado adotam de forma mais acentuada a estratégia - evitação face ao chefe $(\mathrm{F}=4,649 ; \mathrm{p}=, 004)$ e aos colegas $(\mathrm{F}=6,649 ; \mathrm{p}=, 000)$;

- a adoção da estratégia - dominação face ao chefe $(\mathrm{F}=5,427$; $\mathrm{p}=, 006)$, subordinados $(\mathrm{F}=4,542 ; \mathrm{p}=, 013)$ e colegas $(\mathrm{F}=6,573 ; \mathrm{p}=, 002)$ é influenciada pelo local onde trabalha;

- os enfermeiros que têm entre 5 e 15 anos de serviço adotam mais a evitação face ao chefe $(\mathrm{F}=2,834 ; \mathrm{p}=, 042)$ e aos colegas $(\mathrm{F}=3,079 ; \mathrm{p}=, 031)$;

- os enfermeiros que exercem funções nos cuidados gerais adotam mais a estratégia - evitação face ao chefe $(\mathrm{F}=3,267 ; \mathrm{p}=, 031)$ e aos colegas $(\mathrm{F}=7,242 ; \mathrm{p}=, 001)$ comparativamente aos enfermeiros que exercem exclusivamente funções de gestão.

Tendo por referencia os resultados obtidos pelo estudo de associação, entre as três dimensões e o score total da variável empenhamento organizacional e as três dimensões e o score total do empenhamento profissional, constatamos a existência de associações estatisticamente significativas entre estas variáveis. Em concreto, constatamos que:

- o empenhamento afetivo revela uma associação positiva baixa com as dimensões interesse $(\mathrm{r}=, 221 ; \mathrm{p}=, 026)$, relevância $(\mathrm{r}=, 206 ; \mathrm{p}=, 038)$ desafio $(\mathrm{r}=, 259 ; \mathrm{p}=, 009)$ e score total do empenhamento profissional $(\mathrm{r}=, 276 ; \mathrm{p}=, 005)$, o que indicia que quanto maior é o empenhamento afetivo maior é o empenhamento profissional no seu global;

- o empenhamento normativo apresenta uma correlação positiva baixa com a dimensão interesse $(\mathrm{r}=, 284 ; \mathrm{p}=, 004)$ da enfermagem como profissão e o score total do empenhamento profissional ( $r=, 211$; $p=, 033)$, ou seja, os enfermeiros que se sentem obrigados a permanecer na organização revelam 
maior interesse na profissão e um nível mais elevado de empenhamento profissional;

- o empenhamento organizacional total apenas está correlacionado positivamente, de forma baixa, com a dimensão interesse $(r=, 248 ; \mathrm{p}=, 012)$ e de forma muito baixa com o score total do empenhamento profissional $(\mathrm{r}=, 094 ; \mathrm{p}=, 042)$, o que nos permite afirmar que quanto maior o nível de empenhamento organizacional maior o nível de empenhamento profissional.

Considerando os resultados obtidos pelas correlações, tendo por referência as três dimensões e o score total do empenhamento organizacional e as estratégias de resolução de conflitos face ao chefe, subordinados e colegas, constatamos a existência de associações estatisticamente significativas entre estas variáveis. Analisando o nível de significância dos resultados constatamos que:

- o empenhamento afetivo apenas revela uma associação positiva baixa com a estratégia - compromisso face ao chefe $(r=, 238 ; \mathrm{p}=, 016)$, ou seja, quanto maior é o nível de empenhamento afetivo maior é o compromisso enquanto estratégia de resolução de conflitos face ao chefe:

- o empenhamento normativo revela uma associação positiva baixa com a estratégia - compromisso face ao chefe $(r=, 218 ; \mathrm{p}=, 028)$ e a estratégia - evitação face aos colegas $(r=, 211 ; p=, 033)-$, pelo que podemos deduzir que quanto maior é o nível de empenhamento normativo mais utilizam a estratégia compromisso face ao chefe;

- o empenhamento de continuidade tem uma correlação positiva baixa com as estratégias de resolução de conflitos - acomodação face aos subordinados $(\mathrm{r}=, 230 ; \mathrm{p}=, 020)$ e colegas $(\mathrm{r}=, 230 ; \mathrm{p}=, 020)$ - e uma correlação positiva baixa com a estratégia de resolução de conflitos evitação face aos colegas $(r=, 316 ; p=, 001)$-, ou seja, quanto maior é o nível de empenhamento continuidade mais utilizam a estratégia acomodação na resolução de conflitos face aos subordinados e colegas e maior é a utilização da evitação nas estratégias de resolução de conflitos face aos colegas;

- o empenhamento organizacional total está positivamente correlacionado de forma baixa com as estratégias de resolução de conflitos - compromisso face ao chefe $(\mathrm{r}=, 252 ; \mathrm{p}=, 011)$ e a estratégia - evitação face aos colegas $(\mathrm{r}=, 231 ; \mathrm{p}=, 019)$ - e positivamente correlacionado de forma muito baixa com a estratégia - dominação face aos subordinados $(\mathrm{r}=, 196 ; \mathrm{p}=, 049)$ e pelo que podemos afirmar que quanto maior é o nível 
de empenhamento organizacional mais usam as estratégias de resolução de conflitos - compromisso face ao chefe, a estratégia - dominação face aos subordinados e a estratégia - evitação face aos colegas.

Considerando os resultados obtidos pelas correlações, tendo por referência as três dimensões e os score total do empenhamento profissional e as estratégias de resolução de conflitos face ao chefe, subordinados e colegas, constatamos a existência de associações estatisticamente significativas entre estas variáveis. Analisando as associações verificamos que:

- a dimensão interesse da profissão de enfermagem revela uma associação positiva moderada com a estratégia - integração face ao chefe $(\mathrm{r}=, 408 ; \mathrm{p}=, 000)$, subordinados $(\mathrm{r}=, 431 ; \mathrm{p}=, 000)$ e colegas $(\mathrm{r}=, 448$; $\mathrm{p}=, 000)$ e uma associação positiva baixa com a estratégia - acomodação face ao chefe $(\mathrm{r}=, 278 ; \mathrm{p}=, 003)$ e com a estratégia - compromisso face aos subordinados ( $\mathrm{r}=, 247 ; \mathrm{p}=, 012)$ - e colegas $(\mathrm{r}=, 318 ; \mathrm{p}=, 001)$;

- a dimensão relevância da profissão de enfermagem revela uma associação positiva baixa com a estratégia - integração face ao chefe $(\mathrm{r}=, 312 ; \mathrm{p}=, 001)$, subordinados $(\mathrm{r}=, 320 ; \mathrm{p}=, 001)$ - e colegas $(\mathrm{r}=, 288$; $\mathrm{p}=, 003)$-, pelo que podemos deduzir que quanto maior é o nível de relevância mais utilizam a estratégia - integração face ao chefe, subordinados e colegas;

- a dimensão desafio da profissão de enfermagem revela uma associação positiva baixa com a estratégia - integração face ao chefe $(\mathrm{r}=, 336 ; \mathrm{p}=, 001)$ e compromisso face aos colegas $(\mathrm{r}=, 280 ; \mathrm{p}=, 004)$, uma associação moderada com a estratégia - integração face aos subordinados $(\mathrm{r}=, 505 ; \mathrm{p}=, 000)$ e colegas $(\mathrm{r}=, 408 ; \mathrm{p}=, 000)$ e uma associação positiva muito baixa com a estratégia - compromisso face ao chefe ( $\mathrm{r}=, 197$; $\mathrm{p}=, 047)$;

- o empenhamento profissional contextualizado pelo score total está positivamente correlacionado de forma moderada com a estratégia integração face ao chefe $(\mathrm{r}=, 432 ; \mathrm{p}=, 000)$, colegas $(\mathrm{r}=, 500 ; \mathrm{p}=, 000)$ e subordinados ( $\mathrm{r}=, 461 ; \mathrm{p}=, 000)$ e apresenta uma correlação baixa com a estratégia - compromisso face aos subordinados $(\mathrm{r}=, 228$; $\mathrm{p}=, 021)$ e colegas $(\mathrm{r}=, 262 ; \mathrm{p}=, 008)$. Perante estas análises podemos concluir que os enfermeiros mais empenhados profissionalmente demonstram que utilizam mais as estratégias integrativas e de compromisso na resolução de conflitos quer seja face ao chefe, aos subordinados ou aos colegas. 
O estudo das variáveis independentes na predição da variável dependente foi realizado através de modelos de regressão linear múltipla hierárquica, com recurso ao método stepwise. Efetuámos Análises de Regressão Múltipla Passo a Passo, em que testamos, de forma independente, cada uma das dimensões/fatores da escala de Resolução de Conflitos foram utilizadas como variáveis dependentes e as variáveis idade, tempo de serviço na instituição, empenhamento afetivo, empenhamento normativo, empenhamento de continuidade, interesse, relevância e desafio da profissão de enfermagem - como variáveis independentes.

Os resultados obtidos permitem-nos inferir que as variáveis independentes testadas predizem significativamente as estratégias de resolução de conflitos adotadas pelos enfermeiros da seguinte forma: a dimensão interesse da enfermagem como profissão (R2=,167; $F=20,02$; $\mathrm{p}=, 000$ ) é preditiva na adoção da estratégia de resolução de conflitos integração face ao chefe; as variáveis profissionais: tempo de serviço $(\mathrm{R} 2=, 154 ; \mathrm{F}=9,057 ; \mathrm{p}=, 000)$ e as dimensões do empenhamento profissional, interesse $(\mathrm{R} 2=, 082 ; \mathrm{F}=8,968 ; \mathrm{p}=, 003)$; e desafio $(\mathrm{R} 2=, 206$; $\mathrm{F}=8,528 ; \mathrm{p}=, 000)$ predizem significativamente o uso da estratégia de resolução de conflitos - acomodação face ao chefe; a dimensão do empenhamento afetivo ( $\mathrm{R} 2=, 238 ; \mathrm{F}=6,02 ; \mathrm{p}=, 016)$ prediz o uso da estratégia de resolução de conflitos - compromisso face ao chefe; o empenhamento profissional (dimensões desafio - R2=,255; $\mathrm{F}=34,222$; $\mathrm{p}=, 000$ e interesse - $\mathrm{R} 2=, 308 ; \mathrm{F}=7,590 ; \mathrm{p}=, 007)$ prediz significativamente a adoção da estratégia de resolução de conflitos - integração face aos subordinados; o empenhamento profissional (dimensões desafio $\mathrm{R} 2=, 255 ; \mathrm{F}=34,222 ; \mathrm{p}=, 000$ e interesse - R2=,308; $\mathrm{F}=7,590 ; \mathrm{p}=, 007$ ) prediz significativamente a adoção da estratégia de resolução de conflitos evitação face aos subordinados; o empenhamento organizacional (dimensão empenhamento de continuidade - R2=,053; $\mathrm{F}=5,60 ; \mathrm{p}=, 020$ ) prediz de forma significativa a adoção da estratégia de resolução de conflitos - acomodação face aos subordinados; o empenhamento profissional (dimensão desafio - $\mathrm{R} 2=, 084 ; \mathrm{F}=9,225$; $\mathrm{p}=, 003$ ) prediz significativamente a adoção da estratégia de resolução de conflitos compromisso face aos subordinados; o empenhamento profissional (dimensões interesse - R2=,200; $\mathrm{F}=25,05 ; \mathrm{p}=, 000$ e desafio - R2=,254; $\mathrm{F}=7,184 ; \mathrm{p}=$,047) prediz a adoção da estratégia de resolução de conflitos integração face aos colegas e a idade prediz de forma significativa a 
adoção da estratégia de resolução de conflitos - integração face aos colegas; o empenhamento organizacional (nas três dimensões: empenhamento de continuidade - R2=,100; $\mathrm{F}=11,082$; $\mathrm{p}=, 001$, afetivo $\mathrm{R} 2=, 169 ; \mathrm{F}=3,947 ; \mathrm{p}=, 050$ e normativo - $\mathrm{R} 2=, 246 ; \mathrm{F}=9,978 ; \mathrm{p}=, 002$ ) prediz a adoção estratégia de resolução de conflitos - evitação face aos colegas; a idade ( $\mathrm{R} 2=, 100 ; \mathrm{F}=11,082 ; \mathrm{p}=, 001)$ prediz de forma significativa a adoção da estratégia de resolução de conflitos - evitação face aos colegas; o empenhamento organizacional (dimensão empenhamento de continuidade - R2=,053; F=5,598; p=,020) prediz de forma significativa a adoção da estratégia de resolução de conflitos acomodação face aos colegas; o empenhamento profissional (dimensão interesse - R2=,101; $\mathrm{F}=11,28 ; \mathrm{p}=, 001$ ) prediz significativamente a adoção da estratégia de resolução de conflitos - compromisso face aos colegas.

\section{DISCUSSÃO DOS RESULTADOS}

Os enfermeiros demonstram um moderado empenhamento organizacional sendo mais elevado o empenhamento afetivo que o empenhamento normativo ou o empenhamento instrumental. Estes resultados convergem com a evidência empírica de Penley e Gould (1988) nos seus estudos efetuados a enfermeiras, no predomínio do empenho afetivo à organização relativamente às outras dimensões. Estudos de Meyer e Allen (1996) são também concordantes no destaque do empenhamento afetivo, seguindo-se o empenhamento normativo e instrumental.

Quanto ao empenhamento profissional, os enfermeiros apresentam níveis moderados e os resultados revelam que os enfermeiros apresentam valores mais elevados nas dimensões interesse e desafio do que na dimensão relevância da enfermagem como profissão. Estes resultados poderão estar relacionados com o facto de considerarem a enfermagem como uma profissão indispensável, em que se identificam com os valores e objetivos da profissão, que se sentem profissionalmente realizados mas que não terá o reconhecimento social que julgam devido. Numa outra perspectiva, pensamos que o interesse e desafio da enfermagem como profissão que é percepcionado pelos enfermeiros poderão resultar da identificação dos profissionais com os valores e objectivos da enfermagem, da vontade e desejo de exercer a profissão, da intenção de esforço pela mesma (Morrow e Wirth, 1989), da possibilidade de desenvolvimento de competências (Meyer e Allen, 1994), do desenvolvimento de tarefas 
complexas e desafiantes (Blau, 1999), da autonomia e responsabilidade das funções, da perspectiva de desenvolvimento da profissão no âmbito da formação, gestão e investigação (Colliére, 1999). A moderada relevância da enfermagem como profissão sentida pelos enfermeiros pode estar relacionada com desvalorização do seu papel como elemento social, a que não é atribuído valor ao trabalho e a falta de relevância social poderá ser devida ao carácter de invisibilidade associado à profissão em virtude dos enfermeiros ainda não terem afirmado os seus efeitos socioeconómicos no trabalho (Colliére, 1999). A falta de reconhecimento social sentido pelos enfermeiros poderá por em causa a imagem social percepcionada, o que não significa a verdadeira relevância social da profissão de enfermagem.

No que concerne às estratégias de resolução de conflitos, os enfermeiros adotam mais as estratégias de resolução de conflito dominação e acomodação quando em situação conflitual com o chefe e menos as estratégias integrativas e de compromisso. Face aos subordinados os enfermeiros adotam mais as estratégias de evitação perante situações conflituais. Quando a situação conflitual surge com os colegas os enfermeiros adotam mais as estratégias integrativas e de compromisso e menos a estratégia dominação. Podemos afirmar que o empenhamento organizacional influencia a adoção de estratégias de resolução de conflitos conforme a situação conflitual surge com o chefe, com os subordinados ou com os colegas, ou seja o papel de uma pessoa enquanto chefe, colega ou subordinado poderá condicionar o estilo escolhido para lidar com o conflito.

Quanto maior o nível de empenhamento organizacional maior o nível de empenhamento profissional. Os resultados podem estar relacionados com a perceção dos enfermeiros de que os objetivos e valores da enfermagem tendem a ser congruentes com os objetivos e valores organizacionais, bem como a proximidade entre a identificação profissional e a organizacional e os papéis profissionais e organizacionais.

\section{CONCLUSÃO}

Perante os resultados obtidos, podemos concluir que os enfermeiros mais empenhados profissionalmente demonstram que utilizam mais as estratégias integrativas e de compromisso na resolução de conflitos, quer seja face ao chefe, aos subordinados ou aos colegas.

A conciliação dos empenhamentos profissional e organizacional no cotidiano das organizações favorece a consecução dos propósitos e 
objetivos institucionais em consequência da eficiência e da eficácia apresentada pelas pessoas que atuam. O desempenho das equipas de trabalho e o impacto dos resultados dependerão muito das suas competências específicas, da comunicação e do envolvimento das pessoas na sua organização e profissão. Pensar no empenhamento dos profissionais como uma forma de contribuir para a identificação dos seus papéis, implica na usa motivação, interesse e envolvimento. É essencial favorecer e estimular o desenvolvimento do empenhamento afetivo nos indivíduos pelas consequências positivas que ele acarreta na organização e na profissão.

Algumas variáveis sociodemográficas (idade e género) e profissionais (formação em gestão, categoria profissional e local de trabalho) predizem as estratégias de resolução de conflitos adotadas pelos enfermeiros. Há uma correlação positiva entre idade e estratégia evitação face ao chefe; género e estratégia dominação face aos subordinados; formação em gestão e estratégia dominação face ao chefe e subordinados; categoria profissional de enfermeiro e enfermeiro graduado e estratégia evitação face ao chefe e aos colegas; local de trabalho e estratégia dominação face ao chefe.

Face a estas evidências, pensamos que é imprescindível que as organizações possam aplicar o estilo mais adequado de gestão para os seus conflitos, que são inevitáveis. Só aprendendo a gerir eficazmente os seus conflitos internos é que as organizações de saúde estarão preparadas para responder à concorrência que vem do exterior. Neste pressuposto, salientamos que são vários os autores que fomentam a ideia de que o desempenho organizacional beneficia com a estimulação do conflito sob determinadas condições e que a gestão construtiva dos conflitos nas organizações é um elemento essencial para a eficácia organizacional.

\section{FONTES E BIBLIOGRAFIA}

Allen, N., \& Meyer, J. (1996). Affective, continuance, and normative commitment to the organization: an examination of construct validity. Journal of Vocational Behavior, 49, 252-276.

Allen, N. J., \& Meyer, J. P. (1991). A three-component conceptualization of organizational commitment. Human Resource Management Review, 1(1), 61-89.

Allen, N. J., \& Meyer, J. P. (2000). Construct validation in organizational behavior research: The case of organizational commitment. In R. D. Goffin \& E. Helmes (Eds.), Problems and solutions in human 
assessment: Honoring Douglas N. Jackson at Seventy (pp. 285-314). Norwell, MA: Kluwer.

Aranya, N., \& Ferris, K. (1983). Organizational - Professional conflict among U.S. and Israeli professional accountants. Journal of Social Psychology, 119, 153-161.

Bettenhausen, K. L. (1991). Five Years of Groups Research: What We Have Learned and What Needs to be Addressed, Journal of Management, 17(2), 345-381

Blau, G. J. (1999). Early-career job factors influencing the professional commitment of medical technologists. Academy of Management Journal, 42, 687-695.

Blau, G., Paul, A., \& John, N. (1993). On developing a general index of work commitment. Journal of Vocational Behavior, 42, 298-314.

Brahnam, S. D., Margavio, T. M., Hignite, M. A., Barrier, T. B., \& Chin, J. M. (2005). A bender-based categorization for conflict resolution, Journal of Management Development, 24(3), 197-208.

Chen, G., \& Tjosvold, D. (2002). Conflict management and team effectiveness in China: The mediating role of justice, Asia Pacific Journal of Management, 19(4), 557-572.

Collière, M.F. (1989). Promover a vida: Da prática das mulheres de virtude aos cuidados de enfermagem. Lisboa: Sindicato dos Enfermeiros Portugueses.

Cunha, P., Silva, P. I., \& Moreira, M. (2003). (2003). Estilos de gestão de conflito nas organizações: Uma contribuição exploratória para a prática construtiva da resolução de conflitos. Recursos Humanos Magazine, 29, 42-52.

DeChurch, L. A., \& Marks, M. A. (2001). Maximizing the benefits of task conflict: the role of conflict management, International Journal of Conflict Management, 12(1), 4-22.

DeCotiis, T., \& Summers, T., (2007). A path analysis of a model of the antecedents and consequences of organizational commitment. Human Relations, 40(7), 445-470.

Deutsch, M. (2003). Cooperation and Conflict: a personal perspective on the history of the social psychology study of conflict resolution. In M. West, D. Tjosvold e K. Smith (Eds.), International Handboock of Organizational Teamwork and Cooperative Working. Chichester: John Wiley e Sons

Filley, A. C. (1978). Some Normative Issues in Conflict Management, California Management Review, 21(2), 61-66.

Hignite, M. A., Margavio, T. M., \& Chin, J. M. (2002), Assessing the Conflict Resolution Profiles of Emerging Information Systems 
Professionals, Journal of Information Systems Education, 13(4), 315324.

Irving, P.G., Coleman, D.F., \& Cooper, C.L. (1997). Further assessments of a threecomponent model of occupational commitment: Generalizability and differences across occupations. Journal of Applied Psychology, 82(3), 444-452.

Jones, J. (2000). The Impact of Hospital Mergers on Organizational Culture, Organizational Commitment, Professional Commitment, Job Satisfacion, and Intent to Turnover on registered Professional Nurses on Medical-Surgical Hospital Units. Tese de Doutoramento em Filosofia, State University of New York at Buffalo.

Jones, T. E., \& White, C. S. (1985). Relationships Among Personality, Conflict Resolution Styles,and Task Effectiveness. Group and Organization Studies, 10(2),152-167.

Lovelace, K., Shapiro, D.L., \& Weingart, L.R. (2001), Maximizing crossfunctional new product teams ${ }^{\text {ee }}$ innovativeness and constraint adherence: a conflict communications perspective, Academy of Management Journal, 44(4), 779-793.

McIntyre, S. E. (1991). Conflict management by male and female managers as reported by self and by male and female subordinates. Unpublished doctoral thesis. Atlanta, GA: Georgia State University.

Meyer, J. (1997). Organizational commitment. In C. L. Cooper e I. T. Robertson (Eds.), International Review of Industrial and Organizational Psychology, 12, 175-228. Chichester: John Wiley \& Sons.

Meyer, J. P., \& Herscovitch, L. (2001). Commitment in the workplace: Toward a general model. Human Resource Management Review, 11, 299-326.

Meyer, J. P., \& Allen, N. J. (1991). A three-component conceptualization of organizational commitment. Human Resource Management, 1, 6198.

Meyer, J. P., \& Allen, N. J. (1996). Commitment in the workplace: Theory, research, and application. Thousand Oaks: CA, Sage.

Meyer, J. P., Allen, N. J., \& Smith, C. A. (1993). Commitment to organizations and occupations: Extension and test of a three-component conceptualization. Journal of Applied Psychology, 78(4), 538-551.

Meyer, J. P., Bobocel, D. R., \& Allen, N. J. (2003). Development of organizational commitment during the first year of employment: A longitudinal study of pre- and post-entry influences. Journal of Management, 17, 717-733. 
Meyer, J. P., \& Allen, N.J. (1984). Testing the side-bets theory of organizational commitment: some methodological considerations. Journal of Applied Psychology, 69, p.372-378.

Morrow, P. C., \& Wirth, R. E. (1989). Work commitment among salaried professionals. Journal of Vocational Behavior, 34, 40-56.

Penley, L., \& Gould, S., (1988). Etzioniees model of organizational involvement: a perspective for understanding commitment to organizations. Journal of Organizational Behavior, 9, 43-59.

Pestana, M. H., \& Gageiro, J. N. (2008). Análise de dados para ciências sociais: a complementaridade do SPSS ( $5^{\mathrm{a}}$ ed.). Lisboa: Edições Sílabo.

Pruit, D.G., \& Rubin, J. (1986). Social conflict: escalation, stalemate and settlement. New Work: Random House.

Pruitt, D. G. (1971). Choice shifts in group discussion: an introductory review. Journal of Personality and Social Psychology, 20, 339-360.

Rahim, M. (2001). Managing conflict in organizations. Westport: Quorum Books.

Rahim, M. (2002). Toward a Theory of Managing Organizational Conflict. International Journal of Conflict Management,3(13), 206-235.

Rahim, M. (2003). Rahim Organizational Conflict Inventories Experimental Edition. Palo Alto: Consulting Psychologist Press.

Rahim, M., \& Serrano, G. (1996). Avances hacia un modelo de eficácia negociadora. Texto não publicado. Universidade de Santiago de Compostela.

Rahim, M., \& Bonoma, T. (1979). Managing organizational conflict: a model for diagnosis and intervention. Psychological Reports, 44 (3), 1323-1344.

Rego, A., \& Souto, S. (2002). Comprometimento organizacional: Um estudo luso-brasileiro sobre a importância da justiça. Anais do XXVI Encontro da Associação Nacional dos Programas de Pós-Graduação em Administração, Salvador, Brasil, 22-25 Setembro.

Rego, A. (2003). Empenhamento organizacional e ausência psicológica: Afinal quantas dimensões? Revista de Administração de Empresas, 43 (4), 25-35.

Robbins, S.P. (2002). Comportamento organizacional (9a ed.).São Paulo: Prentice Hall.

Thomas, K. (1977). Conflict and negotiation processes in Organizations.In Handbook of Industrial and Organizational Psychology. Palo Alto: Consulting Psychologist Press. 